\title{
Artificial neural networks for prediction of percentage of water absorption of geopolymers produced by waste ashes
}

\author{
ALI NAZARI \\ Department of Materials Science and Engineering, Saveh Branch, Islamic Azad University, Saveh, Iran
}

MS received 18 July 2011; revised 14 February 2012

\begin{abstract}
In the present work, percentage of water absorption of geopolymers made from seeded fly ash and rice husk bark ash has been predicted by artificial neural networks. Different specimens, made from a mixture of fly ash and rice husk bark ash in fine and coarse form together with alkali activator made of water glass and $\mathrm{NaOH}$ solution, were subjected to permeability tests at 7 and 28 days of curing. The curing regime was different: one set cured at room temperature until reaching to 7 and 28 days and the other sets were oven cured for $36 \mathrm{~h}$ at a range of $40-90{ }^{\circ} \mathrm{C}$ and then cured at room temperature for 7 and 28 days. To build the model, training and testing using experimental results from 120 specimens were conducted. According to these input parameters, in the neural networks model, the percentage of water absorption of each specimen was predicted. The training and testing results in the neural networks model have shown a strong potential for predicting the percentage of water absorption of the geopolymer specimens.
\end{abstract}

Keywords. Geopolymer; fly ash; rice husk bark ash; percentage of water absorption; artificial neural networks.

\section{Introduction}

Most building materials have typical porous structure and composed of solid matrix and pores with moisture in them. Permeability of building materials is defined as the movement of liquid and/or gas through a mass of concrete under a constant pressure gradient. It is an inherent property of construction materials that chiefly depends upon the geometric arrangement and characteristics of the constituent materials. The moisture transfer in building materials connects the durability, inside humidity level and energy performance of the building (Fanhong and Maoyu 2008; Tariku et al 2010). Moreover, the moisture transferring in building materials can cause metal corrosion, structure deterioration and improper performance of building insulations.

Inorganic polymers, also known as geopolymers, are X-ray amorphous materials, usually aluminosilicates, composed of a network of randomly arranged silicate and aluminate tetrahedra in conjunction with charge balancing alkali metal cations (Barbosa et al 2000). They generally have high compressive strengths in comparison with concrete specimens together with high water resistivity. Aluminosilicate geopolymers are conventionally synthesized at approximately ambient temperature by reaction of a solid aluminosilicate source, e.g. dehydroxylated kaolin clay (metakaolinite) with an alkali silicate solution under highly alkaline conditions (Davidovits 2008). Industrial wastes such as fly ash or blast furnace slag have also been proposed

\footnotetext{
*Author for correspondence (alinazari84@aut.ac.ir)
}

as solid reactants, especially for low-energy cement applications (Davidovits 2008), but the resulting products are more properly described as alkali-activated cements. The main properties of geopolymers are: quick compressive strength development, low permeability, resistance to acid attack, good resistance to freeze-thaw cycles, and tendency to drastically decrease the mobility of most heavy metal ions contained within the geopolymeric structure (van Jaarsveld et al 1997). Such properties make them interesting structural products, such as concrete replacements in various environments, and immobilization systems for heavy metal containment (Álvarez-Ayuso et al 2008).

The properties of inorganic polymers depend on both the ratio of $\mathrm{Si} / \mathrm{Al}$ and the types of utilized raw material. Fly ash (FA) is recently used as a source material to produce geopolymer because of its suitable chemical composition along with favourable size and shape. Fly ash is a byproduct of coal-fired electric power stations. Literature survey specifies that fly ash is primarily composed of $\mathrm{SiO}_{2}, \mathrm{Al}_{2} \mathrm{O}_{3}$ and $\mathrm{Fe}_{2} \mathrm{O}_{3}$. Since the quality of fly ash depends on the type and quality of coal along with the performance of the power plant, difficulties sometimes remain to control its chemical composition. In order to achieve a suitable chemical composition to produce geopolymers, the preferred method is to blend fly ash with another high silica source (Wongpa et al 2010).

Rice husk-bark ash (RH-BA) is a solid waste generated by biomass power plants using rice husk and eucalyptus bark as fuel. The power plant company providing RH-BA for this research reported that about 450 tons/day of RH-BA are produced and discarded. The major chemical constituent 
of $\mathrm{RH}-\mathrm{BA}$ is $\mathrm{SiO}_{2}$ (about $75 \%$ ) (Sata et al 2007). Therefore, blending FA and $\mathrm{RH}-\mathrm{BA}$ can adjust the ratio of $\mathrm{Si} / \mathrm{Al}$ as required.

Over the last two decades, a different modelling method based on neural networks (ANNs) has become popular and used by many researchers for a wide range of engineering applications. ANNs are a family of massively parallel architectures that solve difficult problems via the cooperation of highly interconnected but simple computing elements (or artificial neurons). Basically, the processing elements of a neural network are analogous to the neurons in the brain, which consist of many simple computational elements arranged in several layers (Pala et al 2005). Some models have been recently proposed to predict Charpy impact behaviour using neural network (Cottrell et al 2007; Pak et al 2009); these models are at their infancy and need to be extended.

As per our knowledge, there are no results reported on utilizing a mixture of FA and RH-BA with seeded distribution of particles to produce geopolymers. In addition, since the concept of geopolymers is completely new and there are only a few works on their properties, application of computer programs like neural networks to predict their properties is rarely reported. The aim of this study is to investigate the percentage of water absorption of geopolymers produced from seeded FA and RH-BA mixture experimentally and presenting suitable model based on artificial neural networks (ANNs) to predict their percentage of water absorption. Both FA and RH-BA with two different particle size distributions have been mixed with different amounts to produce four classes of geopolymers. Percentage of water absorption of the produced specimens has been investigated after specific times of curing. Totally 120 data of permeability tests in different conditions were collected, trained and tested by means of ANNs. The obtained results have been compared by experimental ones to evaluate the software power for predicting the percentage of water absorption of the geopolymer specimens.

\section{Experimental}

The cementitious materials used in this work were FA and RH-BA. Their chemical composition has been illustrated in table 1 (Nazari and Riahi 2012). In addition, figure 1 shows SEM micrograph of the cementitious materials, respectively (Nazari and Riahi 2012). The as-received ashes were sieved and the particles passing the finesses of $150 \mu \mathrm{m}$ and $33 \mu \mathrm{m}$ were ground using Los Angeles mill for 30 and $180 \mathrm{~min}$, respectively which yielded two different samples for each of FA and RH-BA. The average particle sizes obtained for FA were $75 \mu \mathrm{m}$ (coarser FA, named cF in this study) and $3 \mu \mathrm{m}$ (finer FA, named $\mathrm{fF}$ in this study) with BET specific surface of 31.3 and $38.9 \mathrm{~m}^{2} / \mathrm{g}$, respectively. The average particle sizes obtained for $\mathrm{RH}-\mathrm{BA}$ were $90 \mu \mathrm{m}$ (coarser RH-BA, named cR in this study) and $7 \mu \mathrm{m}$ (finer RH-BA, named fR in this study) with BET specific surface of 26 and $33.1 \mathrm{~m}^{2} / \mathrm{g}$, respectively. The four produced samples were used in the experiment. Figure 2 shows parti-

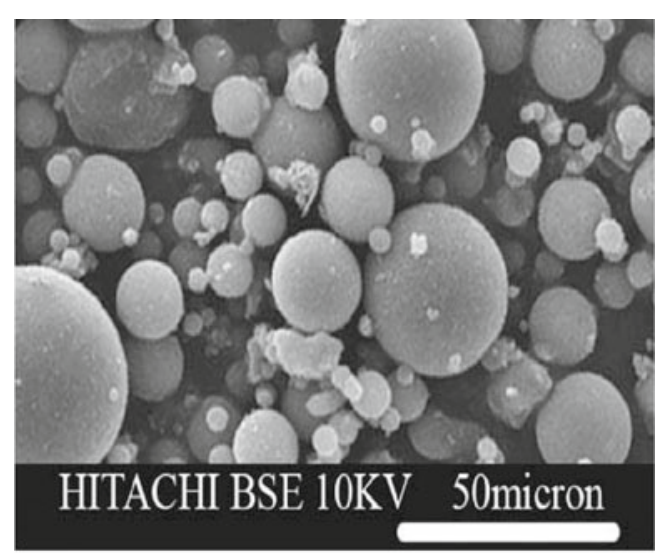

(a)

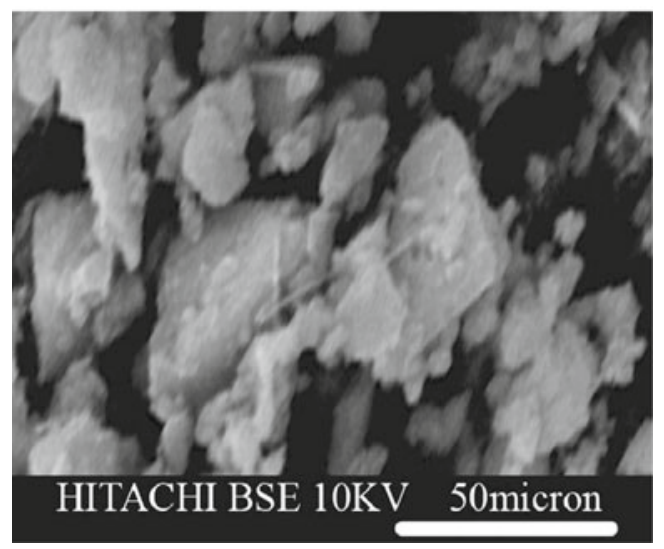

(b)

Figure 1. SEM micrograph of (a) FA and (b) RH-BA used in this study (Nazari and Riahi 2012).

Table 1. Chemical composition of FA, RH-BA and WG (wt\%) (Nazari and Riahi 2012).

\begin{tabular}{lccccccc}
\hline Material & $\mathrm{SiO}_{2}$ & $\mathrm{Al}_{2} \mathrm{O}_{3}$ & $\mathrm{Fe}_{2} \mathrm{O}_{3}$ & $\mathrm{CaO}$ & $\mathrm{SO}_{3}$ & $\mathrm{Na}_{2} \mathrm{O}$ & Loss on ignition \\
\hline FA & $35 \cdot 21$ & $23 \cdot 23$ & $12 \cdot 36$ & $20 \cdot 01$ & $2 \cdot 36$ & $0 \cdot 36$ & -24 \\
RH-BA & $81 \cdot 36$ & 0.4 & $0 \cdot 12$ & $3 \cdot 23$ & $0 \cdot 85$ & $13 \cdot 11$ & - \\
WG & $34 \cdot 21$ & - & - & - & - & 135 \\
\hline
\end{tabular}


cle size distribution of the four produced samples (Nazari and Riahi 2012).

Sodium silicate solution or water glass (WG) and sodium hydroxide $(\mathrm{NaOH})$ were used as the solution part of the mixture. WG was used without modification, but the sodium hydroxide was diluted to different concentrations before use. The chemical composition of the utilized $\mathrm{WG}$ is also given in table 1 (Nazari and Riahi 2012).

Totally 4 series of geopolymer specimens each containing 2 different mixtures of FA and $\mathrm{RH}-\mathrm{BA}$ as illustrated in table 2 (Nazari and Riahi 2012) were prepared for permeability tests. The mixed alkali activator of sodium silicate solution and sodium hydroxide was used. Sodium hydroxide was diluted by tap water to have concentrations of 4,8 and $12 \mathrm{M}$. The solution was left under ambient conditions until excess heat had completely dissipated to avoid accelerating the setting of the geopolymeric specimens. The sodium silicate solution without modification was mixed with sodium hydroxide solution. The ratio of the sodium silicate solution to sodium hydroxide solution was 2.5 by weight for all mixtures because this ratio demonstrated the best properties for fly ash-based geopolymer (Pacheco-Torgal et al 2005, 2007).
For all samples, the mass ratio of alkali activator to FARHA mixture was 0.4 . Pastes were mixed by shaking for 510 min to give complete homogenization. The mixtures were cast in $\phi 30 \times 60 \mathrm{~mm}$ polypropylene cylinders. The mixing was done in an air-conditioned room at $\sim 25^{\circ} \mathrm{C}$. The molds were half-filled, vibrated for $45 \mathrm{~s}$, filled to the top, again vibrated for $45 \mathrm{~s}$, and sealed with a lid. The mixtures were then precured for $24 \mathrm{~h}$ at room temperature (this precuring time has been found to be beneficial to strength development (Bakharev 2005)). Precuring time before application of heat induces significant dissolution of silica and alumina from fly ash and formation of a continuous matrix phase, increasing, therefore, the homogeneity of the geopolymeric materials (Bakharev 2005; Chindaprasirt et al 2007). After the precuring process, samples and molds were placed in a water bath to prevent moisture loss and carbonation of the surface. One batch of these samples was placed in an air-conditioned room at $25^{\circ} \mathrm{C}$. The other batch was put in an oven at elevated temperatures of $50-90{ }^{\circ} \mathrm{C}$ for $36 \mathrm{~h}$. To determine the most effective alkali concentration on percentage of water absorption, one set of the specimens cured at $80{ }^{\circ} \mathrm{C}$ for $36 \mathrm{~h}$ was subjected to permeability tests. Afterwards, the other sets of

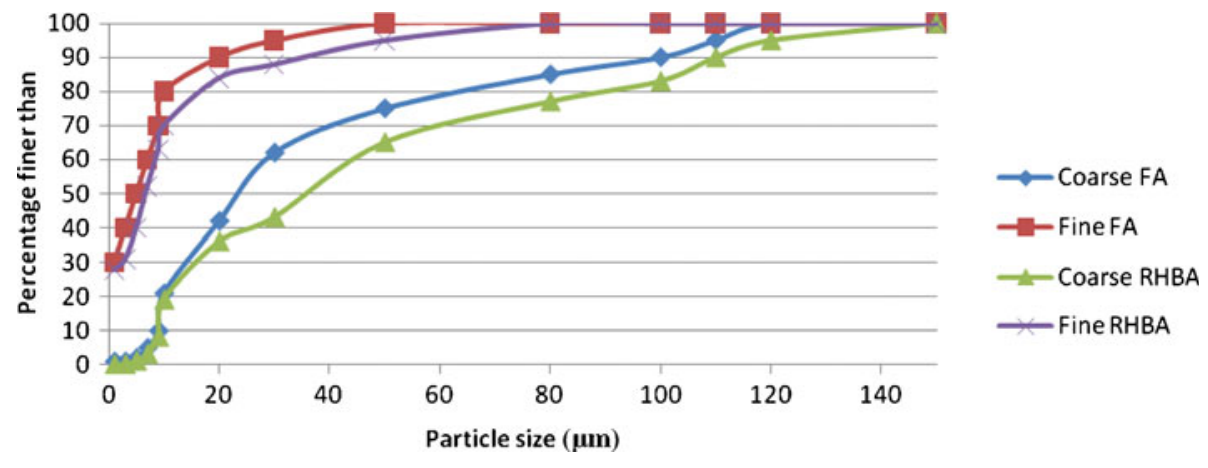

Figure 2. Particle size distribution pattern of different ashes used in this study (Nazari and Riahi 2012).

Table 2. Mixture proportioning of utilized FA and RH-BA to produce geopolymeric specimens (Nazari and Riahi 2012).

\begin{tabular}{|c|c|c|c|c|c|}
\hline $\begin{array}{l}\text { Sample } \\
\text { designation }\end{array}$ & $\begin{array}{l}\text { Weight percent of } \\
\text { fine FA (fF wt } \% \text { ) }\end{array}$ & $\begin{array}{l}\text { Weight percent of } \\
\text { coarse FA (cF wt } \%)\end{array}$ & $\begin{array}{c}\text { Weight percent of } \\
\text { fine RH-BA (fR wt\%) }\end{array}$ & $\begin{array}{c}\text { Weight percent of } \\
\text { coarse RH-BA (cR wt } \%)\end{array}$ & $\begin{array}{l}\mathrm{SiO}_{2} / \mathrm{Al}_{2} \mathrm{O}_{3} \\
\quad \text { ratio }\end{array}$ \\
\hline fF-fR-1 & 60 & 0 & 40 & 0 & $3 \cdot 81$ \\
\hline fF-fR-2 & 70 & 0 & 30 & 0 & 2.99 \\
\hline fF-fR-3 & 80 & 0 & 20 & 0 & $2 \cdot 38$ \\
\hline fF-cR-1 & 60 & 0 & 0 & 40 & $3 \cdot 81$ \\
\hline fF-cR-2 & 70 & 0 & 0 & 30 & 2.99 \\
\hline fF-cR-3 & 80 & 0 & 0 & 20 & $2 \cdot 38$ \\
\hline cF-fR-1 & 0 & 60 & 40 & 0 & $3 \cdot 81$ \\
\hline cF-fR-2 & 0 & 70 & 30 & 0 & 2.99 \\
\hline cF-fR-3 & 0 & 80 & 20 & 0 & $2 \cdot 38$ \\
\hline cF-cR-1 & 0 & 60 & 0 & 40 & $3 \cdot 81$ \\
\hline cF-cR-2 & 0 & 70 & 0 & 30 & 2.99 \\
\hline cF-cR-3 & 0 & 80 & 0 & 20 & $2 \cdot 38$ \\
\hline
\end{tabular}

Alkali activator $(\mathrm{WG}+\mathrm{NaOH})$ to $\mathrm{FA}-\mathrm{RH}-\mathrm{BA}$ mixture ratio is 0.4 . 
Table 3. Percentage of water absorption of geopolymeric specimens (wt\%) (Nazari and Riahi 2012).

\begin{tabular}{|c|c|c|c|c|c|c|c|c|c|c|}
\hline \multirow{2}{*}{$\begin{array}{l}\text { Age of curing } \\
\text { Temperature of oven curing }\end{array}$} & \multicolumn{5}{|c|}{7 day } & \multicolumn{5}{|c|}{28 day } \\
\hline & $25^{\circ} \mathrm{C}$ & $40^{\circ} \mathrm{C}$ & $60^{\circ} \mathrm{C}$ & $80^{\circ} \mathrm{C}$ & $90^{\circ} \mathrm{C}$ & $25^{\circ} \mathrm{C}$ & $40^{\circ} \mathrm{C}$ & $60^{\circ} \mathrm{C}$ & $80^{\circ} \mathrm{C}$ & $90^{\circ} \mathrm{C}$ \\
\hline fF-fR-1 & 1.61 & $1 \cdot 31$ & 1.45 & 1.06 & 1.41 & 1.29 & 1.05 & $1 \cdot 16$ & $0 \cdot 85$ & $1 \cdot 13$ \\
\hline fF-fR-2 & $1 \cdot 26$ & 1.39 & 1 & $0 \cdot 9$ & 1 & 1.01 & $1 \cdot 11$ & $0 \cdot 8$ & 0.72 & 0.8 \\
\hline fF-fR-3 & 1.44 & 1.49 & 1.41 & 1.01 & $1 \cdot 13$ & $1 \cdot 15$ & $1 \cdot 19$ & $1 \cdot 13$ & $0 \cdot 81$ & $0 \cdot 9$ \\
\hline fF-cR-1 & 1.76 & 1.49 & 1.61 & $1 \cdot 12$ & 1.49 & 1.42 & $1 \cdot 2$ & $1 \cdot 3$ & 0.9 & $1 \cdot 2$ \\
\hline fF-cR-2 & $1 \cdot 38$ & $1 \cdot 51$ & 1.09 & 0.98 & 1.09 & $1 \cdot 11$ & $1 \cdot 22$ & 0.88 & 0.79 & 0.88 \\
\hline fF-cR-3 & 1.57 & 1.62 & 1.54 & $1 \cdot 1$ & 1.23 & 1.27 & $1 \cdot 31$ & $1 \cdot 24$ & $0 \cdot 89$ & 0.99 \\
\hline cF-fR-1 & $2 \cdot 11$ & 1.78 & 1.93 & $1 \cdot 33$ & 1.78 & 1.66 & $1 \cdot 4$ & 1.52 & 1.05 & 1.4 \\
\hline cF-fR-2 & 1.65 & $1 \cdot 82$ & $1 \cdot 31$ & $1 \cdot 17$ & $1 \cdot 31$ & $1 \cdot 3$ & 1.43 & 1.03 & 0.92 & 1.03 \\
\hline cF-fR-3 & 1.89 & 1.94 & 1.84 & $1 \cdot 32$ & 1.47 & 1.49 & 1.53 & 1.45 & 1.04 & $1 \cdot 16$ \\
\hline cF-cR-1 & 2.63 & $2 \cdot 22$ & $2 \cdot 41$ & 1.66 & $2 \cdot 22$ & $2 \cdot 04$ & 1.72 & $1 \cdot 87$ & 1.29 & 1.72 \\
\hline cF-cR-2 & $2 \cdot 06$ & $2 \cdot 27$ & 1.64 & 1.46 & 1.64 & 1.6 & $1 \cdot 76$ & $1 \cdot 27$ & $1 \cdot 13$ & $1 \cdot 27$ \\
\hline cF-cR-3 & $2 \cdot 36$ & 2.43 & $2 \cdot 3$ & 1.65 & 1.84 & $1 \cdot 83$ & $1 \cdot 88$ & $1 \cdot 78$ & 1.28 & 1.43 \\
\hline
\end{tabular}

Alkali activator $(\mathrm{WG}+\mathrm{NaOH})$ to $\mathrm{FA}-\mathrm{RH}-\mathrm{BA}$ mixture ratio is $0 \cdot 4$.

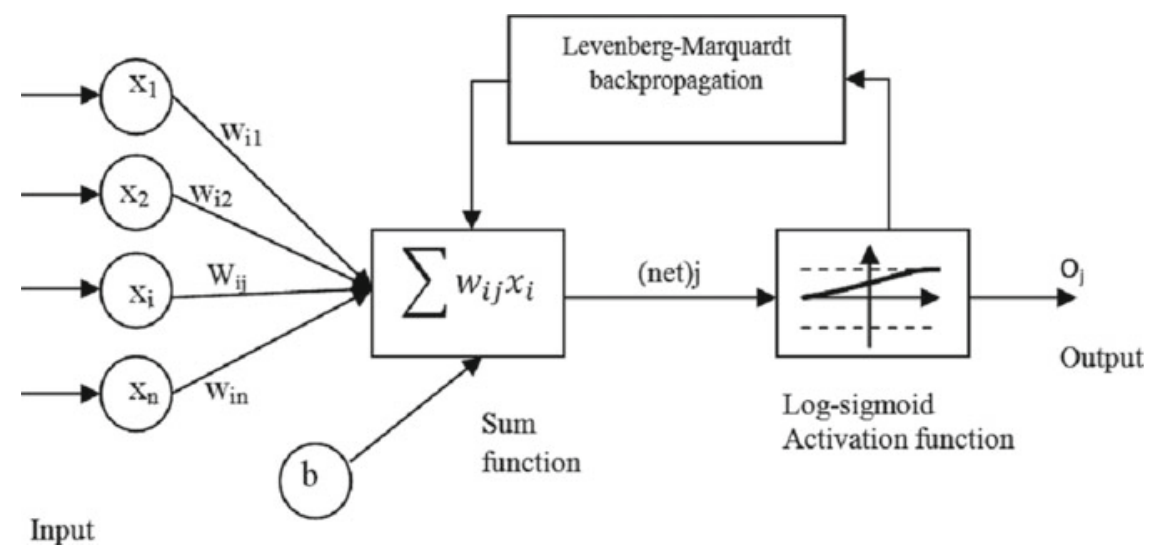

Figure 3. Architecture of applied neural network (Sarıdemir et al 2009).

samples were tested at 7 and 28 days of curing (for the specimens cured in elevated temperature, the time of oven-curing were also considered).

To prepare water permeability testing specimens, $1 \mathrm{~cm}$ from the top and bottom of the samples from each mixture was removed to avoid any effects caused by surface paste. Hence, the samples having $\phi 30 \times 40 \mathrm{~mm}$ were used as representative specimens for each mixture. Non-shrinking epoxy resin was cast around all specimens with a thickness of $25 \mathrm{~mm}$ to prevent water leakage. These specimens were installed in housing cells to test their water permeability. In this work, to evaluate water permeability of the specimens, percentage of water absorption is an evaluation of the pore volume or porosity of concrete after hardening, which is occupied by water in saturated state. Water absorption values of the samples were measured in accordance with the ASTM C 642 after 7 and 28 days of moisture curing adapted to the method done for concrete specimen.

The percentage of water absorption of the produced specimens has been illustrated in table 3 (Nazari and Riahi 2012) for 7 and 28 days of curing. Table 3 (Nazari and Riahi 2012) shows that the best strength has been achieved for fF-fR2 specimen cured at $80{ }^{\circ} \mathrm{C}$ for $36 \mathrm{~h}$ in both 7 and 28 days curing regimes. As table 3 (Nazari and Riahi 2012) shows, the optimum curing condition for all the mixtures is at $80{ }^{\circ} \mathrm{C}$.

\section{Artificial neural networks}

ANNs were developed to model the human brain (Topcu et al 2008). Even an ANN fairly simple and small in size when compared to the human brain, has some powerful characteristics in knowledge and information processing because of its similarity to the human brain. Therefore, an ANN can be a powerful tool for engineering applications (Ince 2004). McCulloch and Pitts (1943) defined artificial neurons for the first time and developed a neuron model as in figure 3. McCulloch and Pitts (1943) network formed the basis for almost all later neural network models. 


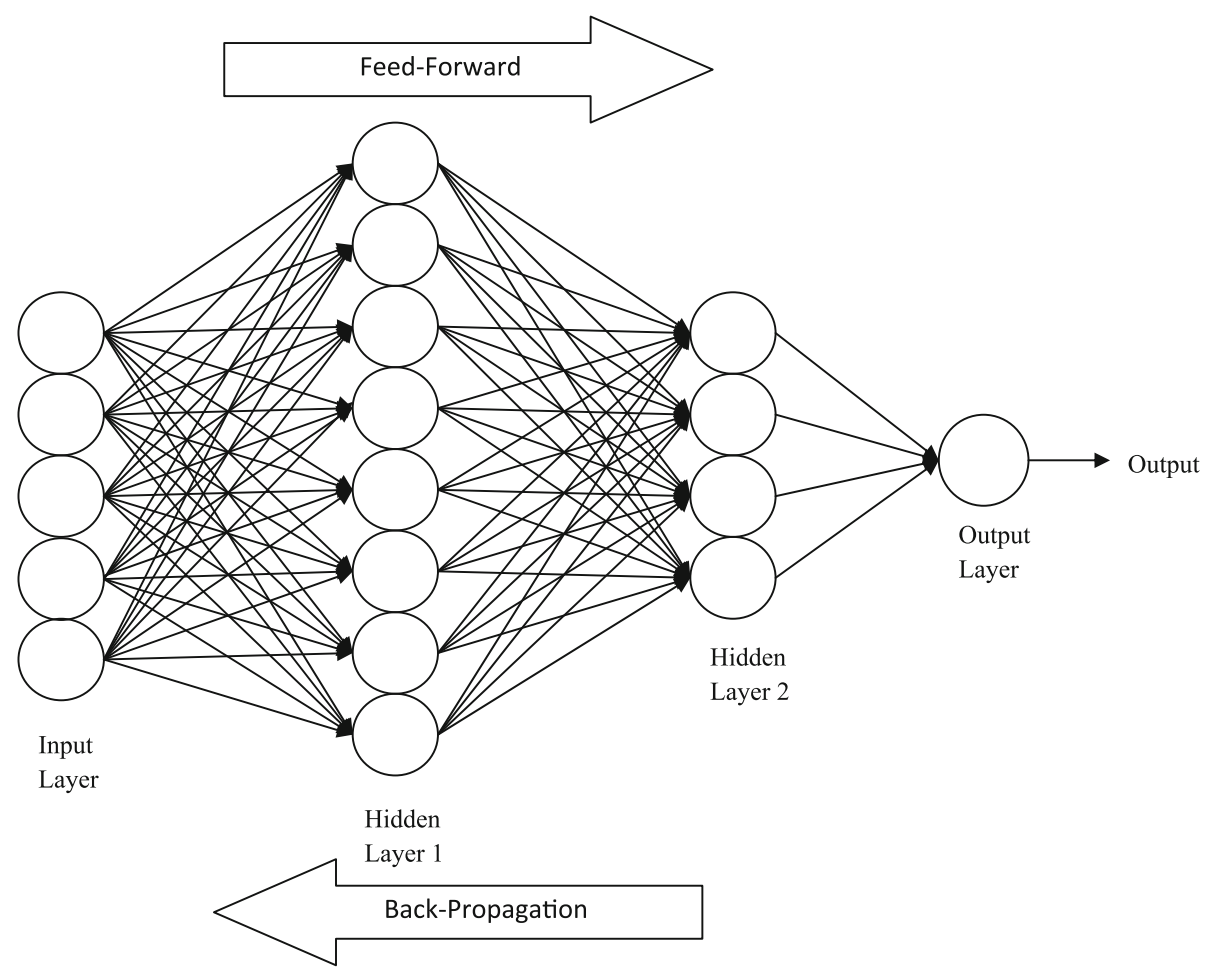

Figure 4. Typical architecture of multilayer perceptron neural network (Sarıdemir et al 2009).

1. Initialize the weights and parameter $\mu(\mu=0.01$ is appropriate).

2. Compute the sum of the squared errors over all inputs $F(w)$

$\mathrm{F}(\mathrm{w})=\mathrm{e}^{\mathrm{T}} \mathrm{e}$

Where $\mathrm{w}=\left[\mathrm{w}_{1}, \mathrm{w}_{2}, \ldots, \mathrm{w}_{\mathrm{n}}\right]$ consists of all weights of the network, $\mathrm{e}$ is the error vector comprising the error for all the training examples.

3. Solve (5) to obtain the increment of weights $\Delta \mathrm{w}$

$\Delta \mathrm{w}=\left[\mathrm{J}^{\mathrm{T}} \mathrm{J}+\mu \mathrm{I}\right]^{-1} \mathrm{~J}^{\mathrm{T}} \mathrm{e}$

Where $\mathrm{J}$ is the Jacobian matrix, $\mu$ is the learning rate which is to be updated using the $\beta$

depending on the outcome. In particular, $\mu$ is multiplied by decay rate $\beta(0<\beta<1)$.

4. Using $\mathrm{w}+\Delta \mathrm{w}$ as the trial $\mathrm{w}$, and judge

IF trial $\mathrm{F}(\mathrm{w})<\mathrm{F}(\mathrm{w})$ in step 2 THEN

$\mathrm{W}=\mathrm{W}+\Delta \mathrm{W}$

$\mu=\mu . \beta(\beta=0.1)$

ELSE

go back to step 2

$$
\begin{aligned}
& \quad \mu=\mu / \beta \\
& \text { go back to step } 4 \\
& \text { END IF }
\end{aligned}
$$

Figure 5. Pseudo-code for LMBP algorithm (Sarıdemir et al 2009).

Afterwards, Rosenblatt (1962) devised a machine called the perceptron that operated much in the same way as the human mind (Sarıdemir et al 2009). Saridemir's perceptions consist of "sensory" units connected to a single layer of McCulloch and Pitts (1943) neurons. Rumelhart et al (1986) derived a learning algorithm for perceptron networks with constituted hidden units. Their learning algorithm is called back-propagation and is now the most widely used learning algorithm. Figure 4 (Sarıdemir et al 2009) shows a typical architecture of a multilayer perceptron neural network with an input layer, two hidden layers and one output layer. As a result of these studies, together with the developments in 


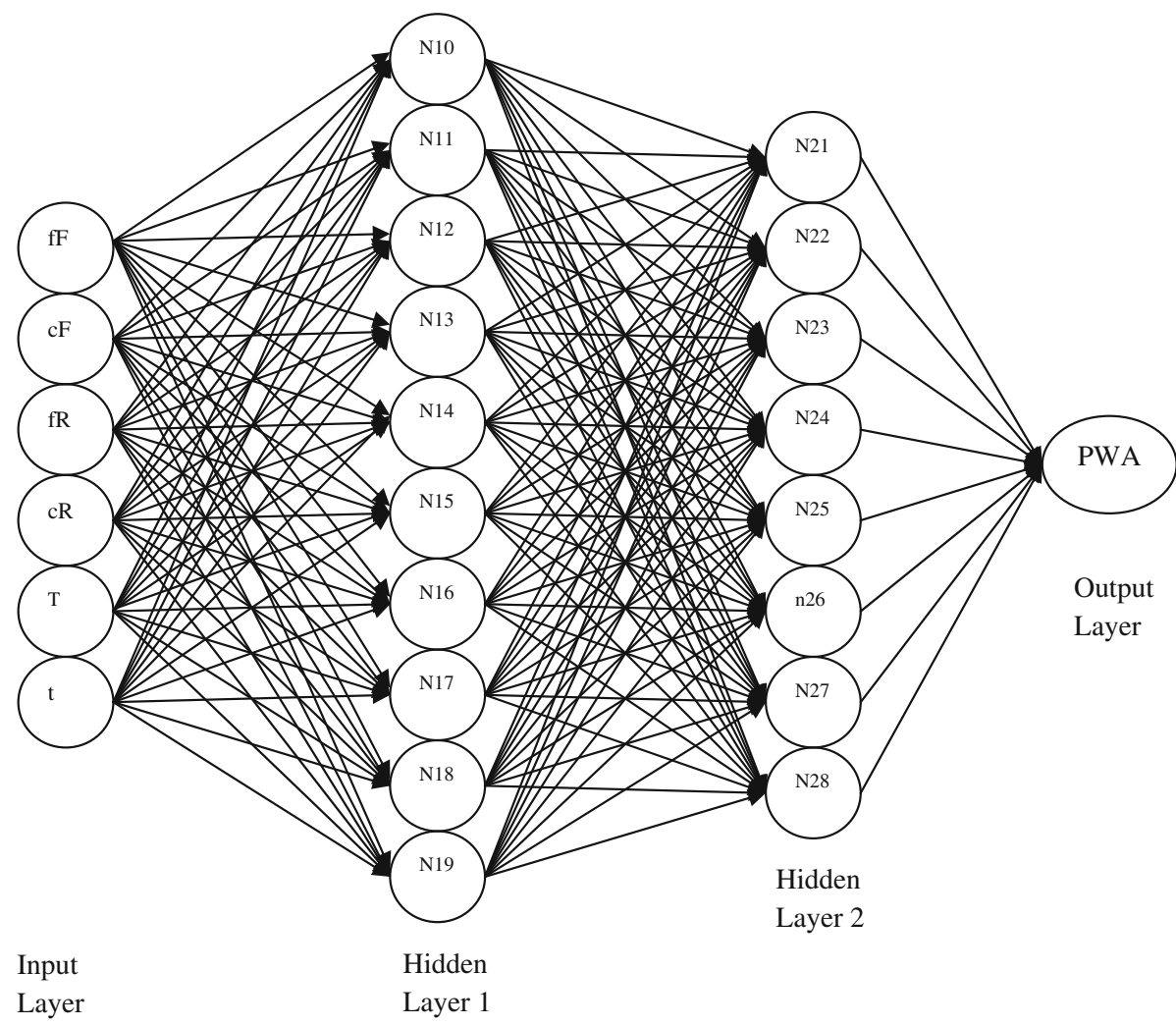

Figure 6. System used in ANN model.

computer technology, using ANN has become more efficient after 1980s (Liu et al 2002).

As can be seen from figure 3, an artificial neuron is composed of five main parts: inputs, weights, sum function, activation function and outputs. Inputs are information that enters the neuron from other neurons from external world. Weights are values that express the outcome of an input set or another process element in the preceding layer on this process element. Sum function is a function that calculates the effect of inputs and weights completely on this process element. This function computes the net input that approaches to a neuron (Gunaydın and Dogan 2004). The weighted sums of the input components (net) ${ }_{j}$ are calculated using (1) as follows:

$$
(\text { net })_{j}=\sum_{i=1}^{n} W_{i j} x_{i}+b
$$

where (net) ${ }_{j}$ is the weighted sum of the $j$ th neuron for the input received from the preceding layer with $n$ neurons, $W_{i j}$ the weight between the $j$ th neuron in the previous layer, $x_{i}$ the output of the $i$ th neuron in the previous layer (Liu et al 2002). $b$ is a fix value as internal addition and $\Sigma$ represents sum function. Activation function is a function that processes the net input obtained from sum function and determines the neuron output. In general, for multilayer feed-forward models as the activation function sigmoid activation function is used. The output of the $j$ th neuron (out) ${ }_{j}$ is computed using
Table 4. Values of parameters used in neural network model.

\begin{tabular}{lc}
\hline Parameters & ANN \\
\hline Number of input layer units & 6 \\
Number of hidden layers & 2 \\
Number of first hidden layer units & 10 \\
Number of second hidden layer units & 8 \\
Number of output layer units & 1 \\
Momentum rate & $0 \cdot 88$ \\
Learning rate & $0 \cdot 70$ \\
Error after learning & $0 \cdot 000050$ \\
Learning cycle & 30.000 \\
\hline
\end{tabular}

(2) with a sigmoid activation function as follows (Gunaydın and Dogan 2004):

$$
O_{j}=f(\text { net })_{j}=\frac{1}{1+\sigma^{-\alpha(\text { net })_{j}}},
$$

where $\alpha$ is a constant used to control the slope of the semilinear region. The sigmoid nonlinearity activates in every layer except in the input layer. The sigmoid activation function represented by (2) gives outputs in $(0,1)$. If it is desired, the outputs of this function can be adjusted to $(-1,1)$ interval. As the sigmoid processor represents a continuous 
function it is particularly used in nonlinear descriptions. Because its derivatives can be determined easily with regard to the parameters within (net) $j$ variable (Liu et al 2002).

LMBP is often the fastest available back-propagation algorithm, and is highly recommended as a first-choice supervised algorithm, although it requires more memory than other algorithms. The standard LMBP training process can be described in the pseudocode of figure 5 (Suratgar et al 2005).

\section{Neural network model structure and parameters}

ANN model in this research has six neurons in the input layer and one neuron in the output layer as demonstrated in figure 6 . The values for input layers were the percentage of fine fly ash in the ashes mixture (fF), the percentage of coarse fly ash in the ashes mixture (cF), the percentage of fine rice husk bark ash in the ashes mixture (fR), the percentage of coarse rice husk bark ash in the ashes mixture $(\mathrm{cR})$, the
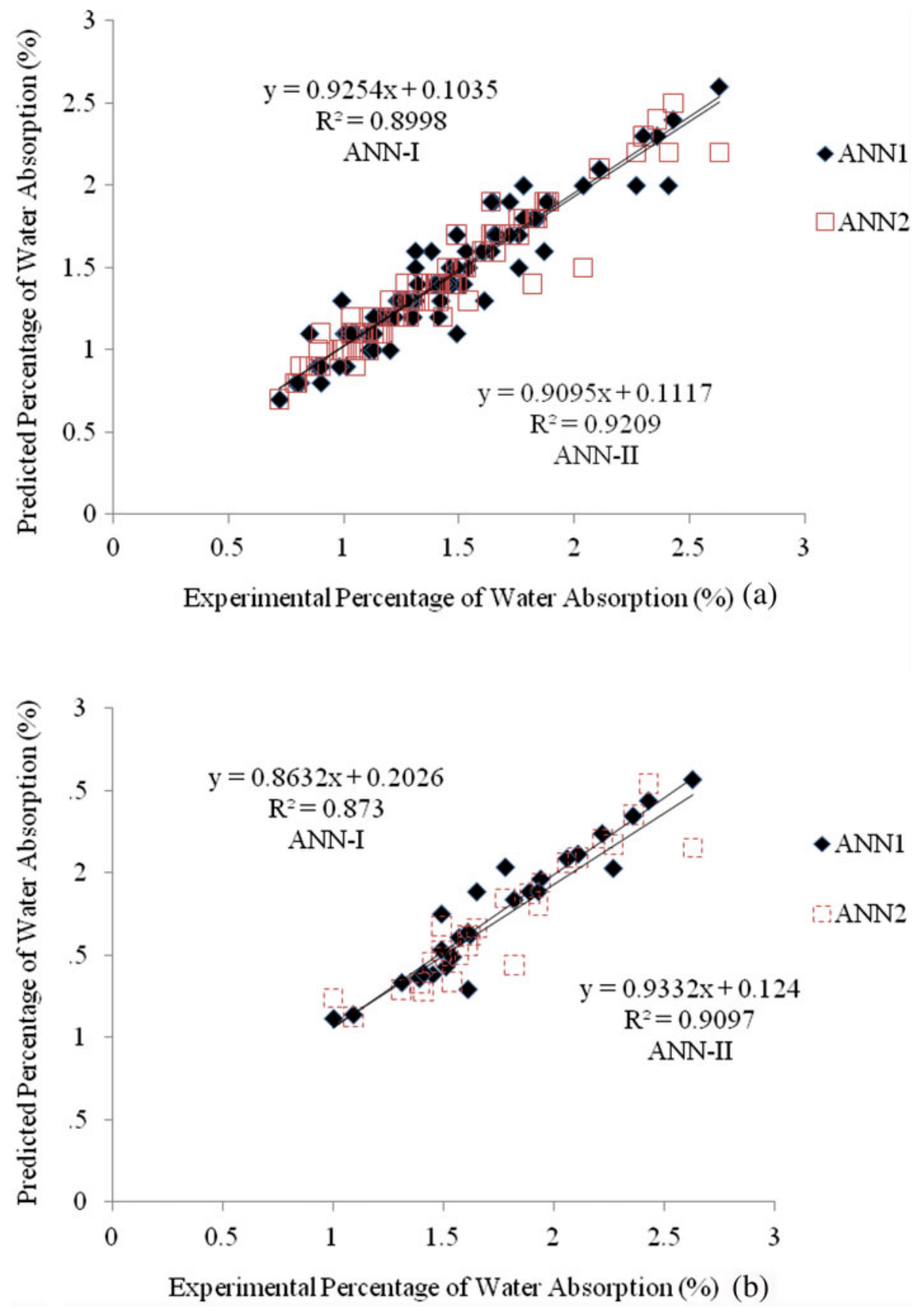

Figure 7. Correlation of measured and predicted percentage of water absorption values of geopolymers in (a) training and (b) testing phase for ANN models. 
Table 5. Data sets for comparison of experimental results with results predicted from ANN models.

\begin{tabular}{|c|c|c|c|c|c|c|c|c|}
\hline $\begin{array}{l}\text { Percentage } \\
\text { of fine fly } \\
\text { ash in ashes } \\
\text { mixture } \\
\text { (fF) }\end{array}$ & $\begin{array}{l}\text { Percentage } \\
\text { of coarse fly } \\
\text { ash in ashes } \\
\text { mixture } \\
\text { (cF) }\end{array}$ & $\begin{array}{l}\text { Percentage } \\
\text { of fine rice } \\
\text { husk bark } \\
\text { ash in ashes } \\
\text { mixture (fR) }\end{array}$ & $\begin{array}{l}\text { Percentage } \\
\text { of coarse rice } \\
\text { husk bark } \\
\text { ash in ashes } \\
\text { mixture (cR) }\end{array}$ & $\begin{array}{l}\text { Temperature } \\
\text { of curing }(T)\end{array}$ & $\begin{array}{c}\text { Time } \\
\text { of water } \\
\text { curing }(t)\end{array}$ & $\begin{array}{c}\text { Percentage } \\
\text { of water } \\
\text { absorption values } \\
\text { obtained from } \\
\text { experiments }(\%)\end{array}$ & $\begin{array}{c}\text { Percentage } \\
\text { of water } \\
\text { absorption values } \\
\text { predicted by } \\
\text { ANN-I model }(\%)\end{array}$ & $\begin{array}{c}\text { Percentage } \\
\text { of water } \\
\text { absorption values } \\
\text { predicted by } \\
\text { ANN-II model }(\%)\end{array}$ \\
\hline 60 & 0 & 40 & 0 & 25 & 7 & 1.61 & $1 \cdot 3$ & 1.6 \\
\hline 70 & 0 & 30 & 0 & 25 & 7 & $1 \cdot 26$ & $1 \cdot 3$ & $1 \cdot 3$ \\
\hline 80 & 0 & 20 & 0 & 25 & 7 & 1.44 & 1.4 & 1.4 \\
\hline 60 & 0 & 0 & 40 & 25 & 7 & 1.76 & 1.7 & 1.8 \\
\hline 70 & 0 & 0 & 30 & 25 & 7 & $1 \cdot 38$ & 1.6 & 1.4 \\
\hline 80 & 0 & 0 & 20 & 25 & 7 & 1.57 & 1.6 & 1.5 \\
\hline 0 & 60 & 40 & 0 & 25 & 7 & $2 \cdot 11$ & $2 \cdot 1$ & $2 \cdot 1$ \\
\hline 0 & 70 & 30 & 0 & 25 & 7 & 1.65 & 1.9 & 1.7 \\
\hline 0 & 80 & 20 & 0 & 25 & 7 & 1.89 & 1.9 & 1.9 \\
\hline 0 & 60 & 0 & 40 & 25 & 7 & 2.63 & $2 \cdot 6$ & $2 \cdot 2$ \\
\hline 0 & 70 & 0 & 30 & 25 & 7 & 2.06 & $2 \cdot 1$ & $2 \cdot 1$ \\
\hline 0 & 80 & 0 & 20 & 25 & 7 & $2 \cdot 36$ & $2 \cdot 3$ & $2 \cdot 4$ \\
\hline 60 & 0 & 40 & 0 & 40 & 7 & $1 \cdot 31$ & $1 \cdot 3$ & $1 \cdot 3$ \\
\hline 70 & 0 & 30 & 0 & 40 & 7 & $1 \cdot 39$ & 1.4 & $1 \cdot 3$ \\
\hline 80 & 0 & 20 & 0 & 40 & 7 & 1.49 & 1.5 & 1.5 \\
\hline 60 & 0 & 0 & 40 & 40 & 7 & 1.49 & 1.7 & 1.7 \\
\hline 70 & 0 & 0 & 30 & 40 & 7 & 1.51 & 1.4 & 1.5 \\
\hline 80 & 0 & 0 & 20 & 40 & 7 & 1.62 & 1.6 & 1.6 \\
\hline 0 & 60 & 40 & 0 & 40 & 7 & 1.78 & 2 & 1.8 \\
\hline 0 & 70 & 30 & 0 & 40 & 7 & 1.82 & 1.8 & 1.4 \\
\hline 0 & 80 & 20 & 0 & 40 & 7 & 1.94 & 2 & 1.9 \\
\hline 0 & 60 & 0 & 40 & 40 & 7 & $2 \cdot 22$ & $2 \cdot 2$ & $2 \cdot 2$ \\
\hline 0 & 70 & 0 & 30 & 40 & 7 & 2.27 & 2 & $2 \cdot 2$ \\
\hline 0 & 80 & 0 & 20 & 40 & 7 & 2.43 & $2 \cdot 4$ & $2 \cdot 5$ \\
\hline 60 & 0 & 40 & 0 & 60 & 7 & 1.45 & 1.4 & 1.5 \\
\hline 70 & 0 & 30 & 0 & 60 & 7 & 1 & $1 \cdot 1$ & $1 \cdot 2$ \\
\hline 80 & 0 & 20 & 0 & 60 & 7 & 1.41 & 1.4 & $1 \cdot 3$ \\
\hline 60 & 0 & 0 & 40 & 60 & 7 & 1.61 & 1.6 & 1.6 \\
\hline 70 & 0 & 0 & 30 & 60 & 7 & 1.09 & $1 \cdot 1$ & $1 \cdot 1$ \\
\hline 80 & 0 & 0 & 20 & 60 & 7 & 1.54 & 1.5 & $1 \cdot 3$ \\
\hline 0 & 60 & 40 & 0 & 60 & 7 & 1.93 & 1.9 & 1.8 \\
\hline 0 & 70 & 30 & 0 & 60 & 7 & $1 \cdot 31$ & 1.6 & $1 \cdot 3$ \\
\hline 0 & 80 & 20 & 0 & 60 & 7 & 1.84 & 1.8 & 1.8 \\
\hline 0 & 60 & 0 & 40 & 60 & 7 & $2 \cdot 41$ & 2 & $2 \cdot 2$ \\
\hline 0 & 70 & 0 & 30 & 60 & 7 & 1.64 & 1.9 & 1.9 \\
\hline 0 & 80 & 0 & 20 & 60 & 7 & $2 \cdot 3$ & $2 \cdot 3$ & $2 \cdot 3$ \\
\hline 60 & 0 & 40 & 0 & 80 & 7 & 1.06 & $1 \cdot 1$ & $1 \cdot 3$ \\
\hline 70 & 0 & 30 & 0 & 80 & 7 & 0.9 & 0.8 & 0.9 \\
\hline 80 & 0 & 20 & 0 & 80 & 7 & 1.01 & 0.9 & 1 \\
\hline 60 & 0 & 0 & 40 & 80 & 7 & $1 \cdot 12$ & $1 \cdot 1$ & $1 \cdot 2$ \\
\hline 70 & 0 & 0 & 30 & 80 & 7 & 0.98 & 0.9 & 1 \\
\hline 80 & 0 & 0 & 20 & 80 & 7 & $1 \cdot 1$ & $1 \cdot 1$ & $1 \cdot 1$ \\
\hline 0 & 60 & 40 & 0 & 80 & 7 & 1.33 & 1.7 & 1.4 \\
\hline 0 & 70 & 30 & 0 & 80 & 7 & $1 \cdot 17$ & $1 \cdot 2$ & $1 \cdot 1$ \\
\hline 0 & 80 & 20 & 0 & 80 & 7 & $1 \cdot 32$ & 1.4 & 1.4 \\
\hline 0 & 60 & 0 & 40 & 80 & 7 & 1.66 & 1.7 & 1.7 \\
\hline 0 & 70 & 0 & 30 & 80 & 7 & 1.46 & 1.5 & 1.4 \\
\hline 0 & 80 & 0 & 20 & 80 & 7 & 1.65 & 1.7 & 1.7 \\
\hline 60 & 0 & 40 & 0 & 90 & 7 & 1.41 & $1 \cdot 2$ & 1.4 \\
\hline 70 & 0 & 30 & 0 & 90 & 7 & 1 & $1 \cdot 1$ & 1 \\
\hline 80 & 0 & 20 & 0 & 90 & 7 & $1 \cdot 13$ & $1 \cdot 2$ & $1 \cdot 1$ \\
\hline 60 & 0 & 0 & 40 & 90 & 7 & 1.49 & $1 \cdot 1$ & 1.4 \\
\hline
\end{tabular}


Table 5. (continued).

\begin{tabular}{|c|c|c|c|c|c|c|c|c|}
\hline $\begin{array}{l}\text { Percentage } \\
\text { of fine fly } \\
\text { ash in ashes } \\
\text { mixture } \\
\text { (fF) }\end{array}$ & $\begin{array}{l}\text { Percentage } \\
\text { of coarse fly } \\
\text { ash in ashes } \\
\text { mixture } \\
\text { (cF) }\end{array}$ & $\begin{array}{l}\text { Percentage } \\
\text { of fine rice } \\
\text { husk bark } \\
\text { ash in ashes } \\
\text { mixture (fR) }\end{array}$ & $\begin{array}{l}\text { Percentage } \\
\text { of coarse rice } \\
\text { husk bark } \\
\text { ash in ashes } \\
\text { mixture (cR) }\end{array}$ & $\begin{array}{l}\text { Temperature } \\
\text { of curing }(T)\end{array}$ & $\begin{array}{c}\text { Time } \\
\text { of water } \\
\text { curing }(t)\end{array}$ & $\begin{array}{c}\text { Percentage } \\
\text { of water } \\
\text { absorption values } \\
\text { obtained from } \\
\text { experiments }(\%)\end{array}$ & $\begin{array}{c}\text { Percentage } \\
\text { of water } \\
\text { absorption values } \\
\text { predicted by } \\
\text { ANN-I model }(\%)\end{array}$ & $\begin{array}{c}\text { Percentage } \\
\text { of water } \\
\text { absorption values } \\
\text { predicted by } \\
\text { ANN-II model }(\%)\end{array}$ \\
\hline 70 & 0 & 0 & 30 & 90 & 7 & 1.09 & $1 \cdot 1$ & $1 \cdot 1$ \\
\hline 80 & 0 & 0 & 20 & 90 & 7 & 1.23 & $1 \cdot 3$ & $1 \cdot 2$ \\
\hline 0 & 60 & 40 & 0 & 90 & 7 & 1.78 & 2 & 1.8 \\
\hline 0 & 70 & 30 & 0 & 90 & 7 & $1 \cdot 31$ & $1 \cdot 3$ & $1 \cdot 3$ \\
\hline 0 & 80 & 20 & 0 & 90 & 7 & 1.47 & 1.4 & 1.4 \\
\hline 0 & 60 & 0 & 40 & 90 & 7 & $2 \cdot 22$ & $2 \cdot 2$ & $2 \cdot 2$ \\
\hline 0 & 70 & 0 & 30 & 90 & 7 & 1.64 & 1.6 & 1.7 \\
\hline 0 & 80 & 0 & 20 & 90 & 7 & 1.84 & 1.8 & 1.8 \\
\hline 60 & 0 & 40 & 0 & 25 & 28 & 1.29 & $1 \cdot 2$ & $1 \cdot 3$ \\
\hline 70 & 0 & 30 & 0 & 25 & 28 & 1.01 & $1 \cdot 1$ & 1 \\
\hline 80 & 0 & 20 & 0 & 25 & 28 & $1 \cdot 15$ & $1 \cdot 2$ & $1 \cdot 1$ \\
\hline 60 & 0 & 0 & 40 & 25 & 28 & 1.42 & $1 \cdot 3$ & 1.4 \\
\hline 70 & 0 & 0 & 30 & 25 & 28 & $1 \cdot 11$ & $1 \cdot 1$ & $1 \cdot 2$ \\
\hline 80 & 0 & 0 & 20 & 25 & 28 & 1.27 & $1 \cdot 3$ & $1 \cdot 3$ \\
\hline 0 & 60 & 40 & 0 & 25 & 28 & 1.66 & 1.7 & 1.6 \\
\hline 0 & 70 & 30 & 0 & 25 & 28 & $1 \cdot 3$ & $1 \cdot 3$ & $1 \cdot 3$ \\
\hline 0 & 80 & 20 & 0 & 25 & 28 & 1.49 & 1.5 & 1.5 \\
\hline 0 & 60 & 0 & 40 & 25 & 28 & $2 \cdot 04$ & 2 & 1.5 \\
\hline 0 & 70 & 0 & 30 & 25 & 28 & 1.6 & 1.6 & 1.6 \\
\hline 0 & 80 & 0 & 20 & 25 & 28 & 1.83 & 1.8 & 1.8 \\
\hline 60 & 0 & 40 & 0 & 40 & 28 & 1.05 & $1 \cdot 1$ & 0.9 \\
\hline 70 & 0 & 30 & 0 & 40 & 28 & $1 \cdot 11$ & 1 & 1 \\
\hline 80 & 0 & 20 & 0 & 40 & 28 & $1 \cdot 19$ & $1 \cdot 2$ & $1 \cdot 2$ \\
\hline 60 & 0 & 0 & 40 & 40 & 28 & $1 \cdot 2$ & $1 \cdot 2$ & $1 \cdot 3$ \\
\hline 70 & 0 & 0 & 30 & 40 & 28 & 1.22 & $1 \cdot 2$ & $1 \cdot 2$ \\
\hline 80 & 0 & 0 & 20 & 40 & 28 & $1 \cdot 31$ & 1.5 & $1 \cdot 3$ \\
\hline 0 & 60 & 40 & 0 & 40 & 28 & 1.4 & 1.7 & 1.5 \\
\hline 0 & 70 & 30 & 0 & 40 & 28 & 1.43 & 1.4 & $1 \cdot 2$ \\
\hline 0 & 80 & 20 & 0 & 40 & 28 & 1.53 & 1.6 & 1.5 \\
\hline 0 & 60 & 0 & 40 & 40 & 28 & 1.72 & 1.9 & 1.7 \\
\hline 0 & 70 & 0 & 30 & 40 & 28 & 1.76 & 1.5 & 1.7 \\
\hline 0 & 80 & 0 & 20 & 40 & 28 & 1.88 & 1.9 & 1.9 \\
\hline 60 & 0 & 40 & 0 & 60 & 28 & $1 \cdot 16$ & $1 \cdot 2$ & $1 \cdot 1$ \\
\hline 70 & 0 & 30 & 0 & 60 & 28 & 0.8 & 0.8 & 1 \\
\hline 80 & 0 & 20 & 0 & 60 & 28 & $1 \cdot 13$ & $1 \cdot 2$ & $1 \cdot 1$ \\
\hline 60 & 0 & 0 & 40 & 60 & 28 & $1 \cdot 3$ & $1 \cdot 2$ & $1 \cdot 3$ \\
\hline 70 & 0 & 0 & 30 & 60 & 28 & 0.88 & 0.9 & 0.9 \\
\hline 80 & 0 & 0 & 20 & 60 & 28 & 1.24 & $1 \cdot 3$ & $1 \cdot 2$ \\
\hline 0 & 60 & 40 & 0 & 60 & 28 & 1.52 & 1.4 & 1.5 \\
\hline 0 & 70 & 30 & 0 & 60 & 28 & 1.03 & $1 \cdot 1$ & $1 \cdot 2$ \\
\hline 0 & 80 & 20 & 0 & 60 & 28 & 1.45 & 1.4 & 1.5 \\
\hline 0 & 60 & 0 & 40 & 60 & 28 & 1.87 & 1.6 & 1.9 \\
\hline 0 & 70 & 0 & 30 & 60 & 28 & $1 \cdot 27$ & $1 \cdot 3$ & 1.6 \\
\hline 0 & 80 & 0 & 20 & 60 & 28 & 1.78 & 1.8 & 1.8 \\
\hline 60 & 0 & 40 & 0 & 80 & 28 & 0.85 & $1 \cdot 1$ & 0.9 \\
\hline 70 & 0 & 30 & 0 & 80 & 28 & 0.72 & 0.7 & 0.7 \\
\hline 80 & 0 & 20 & 0 & 80 & 28 & 0.81 & 0.8 & 0.9 \\
\hline 60 & 0 & 0 & 40 & 80 & 28 & 0.9 & 0.9 & $1 \cdot 1$ \\
\hline 70 & 0 & 0 & 30 & 80 & 28 & 0.79 & 0.8 & $0 \cdot 8$ \\
\hline 80 & 0 & 0 & 20 & 80 & 28 & 0.89 & 0.9 & 1 \\
\hline 0 & 60 & 40 & 0 & 80 & 28 & 1.05 & $1 \cdot 1$ & $1 \cdot 1$ \\
\hline 0 & 70 & 30 & 0 & 80 & 28 & 0.92 & 0.9 & 0.9 \\
\hline
\end{tabular}


Table 5. (continued).

\begin{tabular}{|c|c|c|c|c|c|c|c|c|}
\hline $\begin{array}{l}\text { Percentage } \\
\text { of fine fly } \\
\text { ash in ashes } \\
\text { mixture } \\
\text { (fF) }\end{array}$ & $\begin{array}{l}\text { Percentage } \\
\text { of coarse fly } \\
\text { ash in ashes } \\
\text { mixture } \\
(\mathrm{cF})\end{array}$ & $\begin{array}{l}\text { Percentage } \\
\text { of fine rice } \\
\text { husk bark } \\
\text { ash in ashes } \\
\text { mixture (fR) }\end{array}$ & $\begin{array}{l}\text { Percentage } \\
\text { of coarse rice } \\
\text { husk bark } \\
\text { ash in ashes } \\
\text { mixture (cR) }\end{array}$ & $\begin{array}{l}\text { Temperature } \\
\text { of curing }(T)\end{array}$ & $\begin{array}{c}\text { Time } \\
\text { of water } \\
\text { curing }(t)\end{array}$ & $\begin{array}{c}\text { Percentage } \\
\text { of water } \\
\text { absorption values } \\
\text { obtained from } \\
\text { experiments }(\%)\end{array}$ & $\begin{array}{c}\text { Percentage } \\
\text { of water } \\
\text { absorption values } \\
\text { predicted by } \\
\text { ANN-I model }(\%)\end{array}$ & $\begin{array}{c}\text { Percentage } \\
\text { of water } \\
\text { absorption values } \\
\text { predicted by } \\
\text { ANN-II model }(\%)\end{array}$ \\
\hline 0 & 80 & 20 & 0 & 80 & 28 & 1.04 & $1 \cdot 1$ & 1 \\
\hline 0 & 60 & 0 & 40 & 80 & 28 & 1.29 & $1 \cdot 3$ & $1 \cdot 3$ \\
\hline 0 & 70 & 0 & 30 & 80 & 28 & $1 \cdot 13$ & $1 \cdot 1$ & $1 \cdot 1$ \\
\hline 0 & 80 & 0 & 20 & 80 & 28 & 1.28 & $1 \cdot 3$ & $1 \cdot 2$ \\
\hline 60 & 0 & 40 & 0 & 90 & 28 & $1 \cdot 13$ & 1 & $1 \cdot 1$ \\
\hline 70 & 0 & 30 & 0 & 90 & 28 & $0 \cdot 8$ & 0.8 & 0.8 \\
\hline 80 & 0 & 20 & 0 & 90 & 28 & 0.9 & 0.9 & 0.9 \\
\hline 60 & 0 & 0 & 40 & 90 & 28 & $1 \cdot 2$ & 1 & $1 \cdot 2$ \\
\hline 70 & 0 & 0 & 30 & 90 & 28 & 0.88 & $1 \cdot 1$ & 0.9 \\
\hline 80 & 0 & 0 & 20 & 90 & 28 & 0.99 & $1 \cdot 3$ & 1 \\
\hline 0 & 60 & 40 & 0 & 90 & 28 & 1.4 & 1.4 & 1.4 \\
\hline 0 & 70 & 30 & 0 & 90 & 28 & 1.03 & $1 \cdot 1$ & $1 \cdot 1$ \\
\hline 0 & 80 & 20 & 0 & 90 & 28 & $1 \cdot 16$ & $1 \cdot 2$ & 1 \\
\hline 0 & 60 & 0 & 40 & 90 & 28 & 1.72 & 1.7 & 1.7 \\
\hline 0 & 70 & 0 & 30 & 90 & 28 & $1 \cdot 27$ & $1 \cdot 3$ & 1.4 \\
\hline 0 & 80 & 0 & 20 & 90 & 28 & 1.43 & 1.4 & $1 \cdot 2$ \\
\hline
\end{tabular}

temperature of curing $(T)$ and the time of water curing $(t)$. The value for output layer was percentage of water absorption (PWA). Two hidden layers with ten and eight neurons were used in the architecture of multilayer neural network because of its minimum absolute percentage error values for training and testing sets. The neurons of neighbouring layers are completely interconnected by weights. Finally, the output layer neurons produce the network prediction as a result.

In this study, the back-propagation training algorithm has been utilized in feed-forward two hidden layers. Backpropagation algorithm, as one of the most well known training algorithms for the multilayer perceptron, is a gradient descent technique to minimize the error for a particular training pattern in which it adjusted the weights by a small amount at a time (Suratgar et al 2005). The nonlinear sigmoid activation function was used in the hidden layer and the neuron outputs at the output layer. Momentum rate and learning rate values were determined and the model was trained through iterations. The trained model was only tested with the input values and the predicted results were close to experimental results. The values of parameters used in neural network model are given in table 4 .

Totally 120 data of permeability tests in different conditions were collected, trained and tested by means of ANNs. Among 120 experimental sets, 94 sets were randomly chosen as a training set for the ANN-I and ANN-II modelling and the remaining 26 sets were used as testing the generalization capacity of the proposed models.

To make a decision on the completion of the training processes, two termination states are declared: state 1 (ANN-I model) means that the training of neural network ended when the maximum epoch of process reached (1000) while state 2 (ANN-II model) means the training ended when minimum error norm of network gained.

The performance of a ANN model mainly depends on the network architecture and parameter settings. One of the most difficult tasks in ANN studies is to find this optimal network architecture, which is based on the determination of numbers of optimal layers and neurons in the hidden layers by a trial and error approach. The assignment of initial weights and other related parameters may also influence the performance of ANN to a great extent. However, there is no well defined rule or procedure to have an optimal network architecture and parameter settings where the trial and error method still remains valid. This process is very time consuming (Guzelbey et al 2006).

In this study, the Matlab ANN toolbox is used for ANN applications. To overcome optimization difficulty, a program has been developed in Matlab which handles the trial and error process automatically (Guzelbey et al 2006). The program tries various number of layers and neurons in the hidden layers both for the first and second hidden layers when the highest root mean squared error (RMSE) of the testing set, as the training of the testing set is achieved (Guzelbey et al 2006).

\section{Results and discussion}

In this study, the error arose during the training and testing of ANN-I and ANN-II models and can be expressed as absolute 
fraction of variance $\left(R^{2}\right)$ which are calculated by (3) (Topcu and Sarıdemir 2008):

$$
R^{2}=1-\left(\frac{\sum_{i}\left(t_{i}-o_{i}\right)^{2}}{\sum_{i}\left(o_{i}\right)^{2}}\right),
$$

where $t$ is the target value and $o$ the output value.

All of the results obtained from experimental studies and predicted by using the training and testing results of ANN-I and ANN-II models are given in figures $7 \mathrm{a}$ and $\mathrm{b}$, respectively. The linear least square fit line, its equation and the $R^{2}$ values were shown in these figures for the training and testing data. Also, input values and experimental results with training and testing results obtained from ANN-I and ANN-II models are given in table 5 . As it is visible in figure 7, values obtained from the training and testing in ANN-I and ANN-II models are very close to the experimental results. The result of testing phase in figure 7 shows that the ANN-I and ANN-II models are capable of generalizing between input and output variables with reasonably good predictions.

The performance of ANN-I and ANN-II models are shown in figure 7. The best value of $R^{2}$ is $99.90 \%$ for training set in the ANN-II model. The minimum values of $R^{2}$ is $95.74 \%$ for testing set in ANN-I model. All of $R^{2}$ values show that the proposed ANN-I and ANN-II models are suitable and can predict the permeability values very close to the experimental values.

\section{Conclusions}

From the experimental procedure, the following results were obtained:

(I) ANNs can be used an alternative approach for the evaluation of the effect of seeded mixture of FA and $\mathrm{RH}-\mathrm{BA}$ on percentage of water absorption values of geopolymer specimens.

(II) Comparison between ANNs in terms of $R^{2}$ showed that ANNs models are capable to predict suitable results for percentage of water absorption values of geopolymer specimens.

\section{References}

Álvarez-Ayuso E et al 2008 J. Hazard. Mater. 154175

Bakharev T 2005 Cement Concr. Res. 351224
Barbosa V F F, MacKenzie K J D and Thaurmaturgo C 2000 Int. J. Inorg. Mater. 2309

Chindaprasirt P, Chareerat T and Sirivivatnanon V 2007 Cement Concr. Compos. 29224

Cottrell G A, Kemp R, Bhadeshia H K D H, Odette G R and Yamamoto T 2007 J. Nucl. Mater. 367603

Davidovits J 2008 Geopolymer chemistry and applications (St. Quentin: Geopolymere Institut)

Fanhong K and Maoyu Z 2008 Energy Build 401614

Gunaydın H M and Dogan S Z 2004 Int. J. Project Manage. 22595

Guzelbey I H, Cevik A and Erklig A 2006 J. Constr. Steel Res. 62 962

Ince R 2004 Eng. Fract. Mech. 712143

Liu S W, Huang J H, Sung J C and Lee C C 2002 Comput. Meth. Appl. Mech. Eng. 1912831

McCulloch W S and Pitts W 1943 Bull. Math. Biophys. 5115

Nazari A and Riahi S 2012 J. Non-Cryst. Solids 35840

Pacheco-Torgal F, Castro-Gomes J P and Jalali S 2005 Studies about mix composition of alkali-activated, mortars using waste mud from Panasqueira. in Proceedings of the engineering conference (Covilha, Portugal: University of Beira Interior)

Pacheco-Torgal F, Castro-Gomes J and Jalali S 2007 Cem. Concr. Res. 37933

Pak J, Jang J, Bhadeshia H K D H and Karlsson L 2009 Mater. Manuf. Process. 2416

Pala M, Ozbay O, Oztas A and Yuce M I 2005 Constr. Build. Mater. 21384

Rosenblatt F 1962 Principles of neuro dynamics: perceptrons and the theory of brain mechanisms (Washington DC: Spartan Books)

Rumelhart D E, Hinton G E and William R J 1986 Learning internal representation by error propagation, in Proceeding parallel distributed processing foundation (eds) D E Rumelhart and J L McClelland (Cambridge: MIT Press)

Sarıdemir M, Topcu I B, Ozcan F and Severcan M H 2009 Constr. Build. Mater. 231279

Sata V, Jaturapitakkul C and Kiattikomol K 2007 Constr. Build Mater. 211589

Suratgar A A, Tavakoli M B and Hoseinabadi A 2005 World Acad. Sci. Eng. Technol. 646

Tariku F, Kumaran K and Fazio P 2010 Int. J. Heat Mass Tran. 53 3035

Topcu I B and Sarıdemir M 2008 Comp. Mater. Sci. 41305

Topcu I B, Karakurt C and Sarıdemir M 2008 Mater. Design 29 1986

van Jaarsveld J G S, van Deventer J S J and Lorenzen L 1997 Miner. Eng. 10659

Wongpa J, Kiattikomol K, Jaturapitakkul C and Chindaprasirt $\mathrm{P}$ 2010 Mater. Design 314748 